\title{
Numerical homogenization of the foamed metal structures
}

\author{
A. John*, M. John**, A. Bartela*** \\ *Silesian University of Technology, Konarskiego 18A, 44-100 Gliwice, Poland, E-mail: antoni.john@polsl.pl \\ **Silesian University of Technology, Konarskiego 18A, 44-100 Gliwice, Poland, E-mail: malgorzata.john@polsl.pl \\ ***Silesian University of Technology, Konarskiego 18A, 44-100 Gliwice, Poland, E-mail: bartela91@gmail.com \\ cross $^{\text {ref }}$ http://dx.doi.org/10.5755/j01.mech.22.5.16689
}

\section{Introduction}

Current trends in the design of new materials put great emphasis on the development of all kinds of composite materials and highly porous. Such materials with much lower densities exhibit good and sometimes even better mechanical properties than the native material. Large growth was recorded in the field of highly porous materials, which in their structure have a cavity filled with gas. These structures are often referred foams, and formed from different types of materials from the group of metals, polymers and ceramics. Foamed metals, also called metal plans are pure metals or alloys that have in their structure a significant amount of intentionally introduced gas bubbles. The volume of the pores in the metal foam spans between $40 \%$ and $90 \%$, but also more common foam having the pores in its structure [1-3].

Foamed metals have various kinds of pores can be sealed, or each void is a separate component and can't be combined with others and the pores open, which they are connected to other voids, or the entire structure has the form of a beam, wherein each gas bubble combined and all neighboring base material takes the form of metal fibers connecting the foam structure. Gases used primarily air, but also other uses, especially when the foamed metal is reactive with air, which could cause corrosion and degradation of the structure. It is used as foam metal of a different type of material such as copper, nickel, zinc, lead, molybdenum, rhenium, stainless steel, tin and titanium, and alloys such as nickel-iron, nickel and copper, nickel and chromium, tungsten, and nickel and of iron, nickel and chromium. Currently it is used for foaming in wide use of the most popular serial or a structural material which is solid, except for stainless steel, this is due to the flammability of the liquid steel in contact with oxygen and ease of corrosion of the material. The foamed metals where the walls are very thin bubbles through which corrosion is very dangerous, because it can rapidly destroy the cell structure and completely destroy the entire structure of the material. So to create the foam and prevent its destruction would be used in the process of its production as a cover and fill the pores of the inert gases, which affects a significant increase in the price of a material and causes that do not produce such a structure [2-4].

Currently expanded metal is used mainly as components of a vibration damping or impact-absorbing casing. This is due to the high energy absorption property of the metal foam, many times larger than the native material $[1,5]$ (Fig. 1).

A very interesting feature of metal foams is their property of absorbing high energy, thanks to the properties used in various types of packaging for impact protection as vibration isolators - in many types of machine tools and other equipment and sometimes even the same components. An example of such use of a metal foam may be a new type of gears into which the elements of expanded metal between the hub and the ring gear which reduces the noise throughout the transmission, and reduces the impact of the teeth themselves and the weight of the mix (Fig. 2, [6, 7]). Increasingly used also in this property foams in automotive, wherein the foam metal used to reinforce the hollow profile in the design of safe crumple zones. Crumple zones safe are responsible for absorbing the energy created during impact.

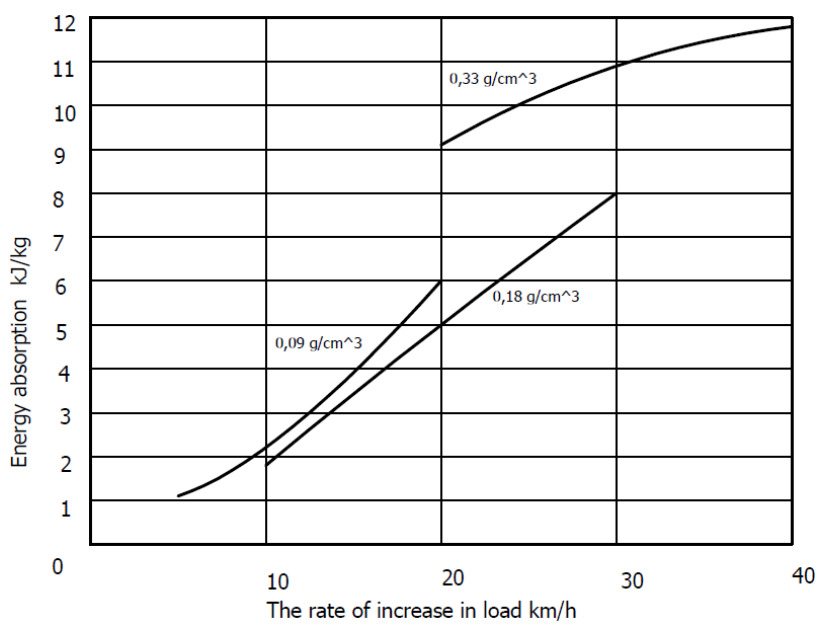

Fig. 1 Energy absorption chart [1]

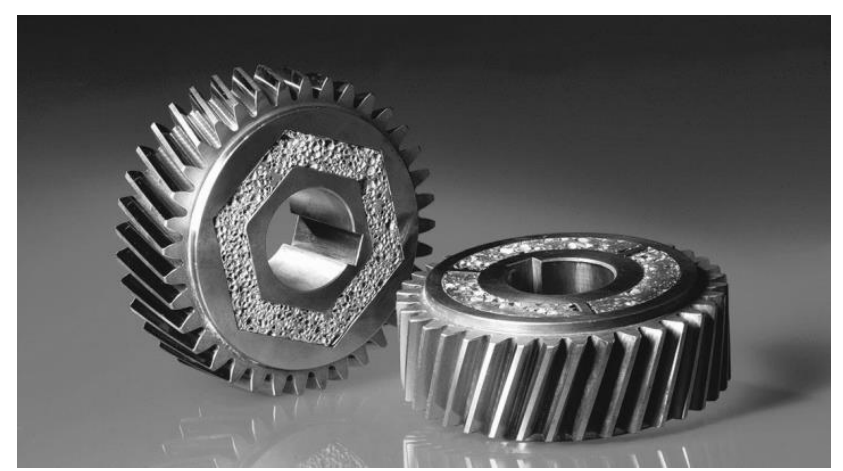

Fig. 2 Gears with a layer of metal foam [7]

In addition to building components to protect against explosions it is also used as a refractory elements protecting load-bearing elements or at risk of ignition from the possibility of ignition and damage caused by the impact of an open flame. They are also used as components of heatconductive or insulating, depending on what is their density and the material from which they are made. Using foam cop- 
per, we can get good conductive elements at very high savings expensive material which is copper, and the way to reduce the weight of components (Fig. 3, [8]). They are used also in the shipping industry as a lightweight materials to improve buoyancy and floatability all kinds of watercraft.

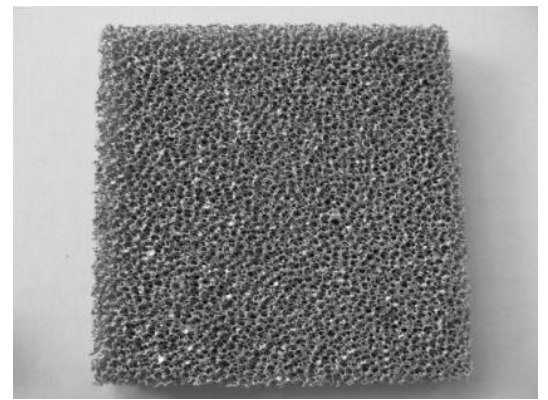

Fig. 3 The conductive copper foam [8]

In view of their high porosity and a highly developed surface, closely linked to their porosity or internal relative density and cell type, they are frequently used as catalysts and filters in a wide range of different types of chemical reactions. As that in this branch of the application is important to the ability to pass through a foam of various kinds of gases and liquids used herein open-cell foam.

Because that they exhibit absorption and conduction are rarely used as supporting structures. This is influenced by their relatively low strength due to very low relative density. Low density makes the cell walls inside are very thin and irregularly distributed in the structure by which quickly destroyed or weakened.

In the paper multi-scale modeling of the foamed metal structures using numerical homogenization algorithm is prescribed. The first, numerical model of heterogeneous porous simplified structures of typical foamed metal, based on the FEM was built. Next, a micro RVE model representing elementary volume of macroscopic model was constructed. Material parameters of the considered structure were determined with use of numerical homogenization algorithm. In the work the different RVE models of structure were created and their properties were compared at different relative density, different numbers and the size and structure of the arrangement of voids.

The main goal of the work was to test how changes in the geometric parameters influence on changing the mechanical parameters of structures, mainly material parameters. It can be useful in modeling new materials with expected material parameters.

\section{Numerical homogenization}

Numerical homogenization is mainly for calculating the variables defining the status and parameters of the microstructure in such a way that by using these variables can be modelled macrostructure materials in such a way as if it was made of homogeneous material, a phenomenon occurring in the microstructure which affect the macrostructure are represented by the calculated variables $[9,10]$. The advantages of this method are:

- no need putting requirements in relation to assumptions of constitutive centre macroscopic;

- allows the consideration of large deformations in both micro and macro;
- makes it possible to use any of the techniques of numerical calculation in both scales;

- the ability to modify the micro to the macro level of analysis; non-linear.

- the possibility of using the issues of dynamic and

The models with which to model and explore the structure of the micro call RVE (representative volume element). RVE models should represent the micro-structure to the extent possible to identify the properties of the medium in composition. It is important RVE small enough to make it simple as possible so that we can carry out its detailed analysis, yet large enough to be able to represent the microscopic structure of the tested structure. If the model structure is homogeneous typically comprise a so-called unit cell, or RVE model that has only one inclusion, in this case the void. use RVE:

Basically there are three types of approaches to the

- Adoption of a constitutive law at the macro level, averaging material parameters.

- Adoption of a constitutive law at the macro level, testing of material parameters.

- No explicit constitutive law at the macro level, testing of material parameters and calculating the actual stress tensor and effective tangential material parameters.

The simplest approach is the aforementioned averaging material parameters, the computation of a tensor, the average material constants. This may be the arithmetic mean or harmonic mean. The values determined by these methods often vary considerably and are a lower bound and upper tensor properties of the material. This method has a low accuracy which is caused by the fact that it does not take the shape of inclusions, and in this case the air bubbles, that is, we assume that our material is completely isotropic. This approach is sufficiently accurate only in the case of calculation of the inertia, as well modelled averaging the values of these parameters.

Another approach is a numerical testing of material parameters. In this case, we determine the components of the tensor material parameters on the basis of the selected element RVE load cases. Apply the burden of stress or strain without regard to volume forces, in the case of $3 \mathrm{D}$ element it is necessary to perform six samples corresponding to the six component tensor material parameters. These attempts, for example, deformation in three main directions $\mathrm{x}, \mathrm{y}$ and $\mathrm{z}$ in the absence of other loads, and also in the tangential direction of the three components $\mathrm{YZ}, \mathrm{XZ}$ and $\mathrm{XY}$ whereas searched tensor is symmetric. This method in compared with the previous one takes into account the internal structure and anisotropic properties of the structure. That is necessary when the inclusions in the material are irregularly spaced.

The study used precisely this method in numerical terms. The methodology is the same as in the classic approach, which is performed six studies with six different boundary conditions, and then averages the strain and stress in a model using the following equations:

$$
<\varepsilon_{i j}>=\frac{1}{V_{R V E}} \int_{V_{R V E}} \varepsilon_{i j} d V_{R V E}
$$




$$
<\sigma_{i j}>=\frac{1}{V_{R V E}} \int_{V_{R V E}} \sigma_{i j} d V_{R V E},
$$

where $\left\langle\varepsilon_{i j}\right\rangle,\left\langle\sigma_{i j}\right\rangle$ is averaged strain and stress at macro scale respectively; $V_{R V E}$ is volume of RVE element.

Next when these values $\left\langle\varepsilon_{i j}\right\rangle$, $\left\langle\sigma_{i j}\right\rangle$ are designated we substitute them into a matrix in Eq. (3) and then it is possible to calculate elasticity matrix $\boldsymbol{C}$ of equivalent homogenous material using the matrix Eq. (4).

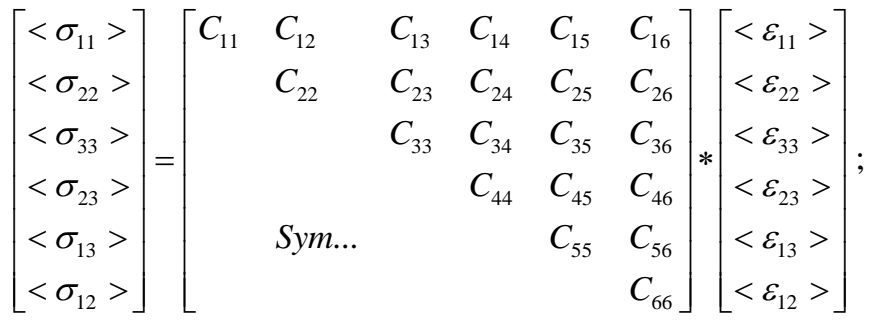

$$
C=<\sigma_{i j}>*<\varepsilon_{i j}>^{-1} .
$$

It is important that homogenization process is possible only if the scale separation condition is satisfied (5):

$$
l / L \ll 1,
$$

where $l$ is characteristic dimension for the scale of heterogeneity; $L$ is characteristic dimension for the scale of homogeneity.

In case of periodic structures, periodic boundary condition should be used. Periodic boundary displacement $u(6)$ and anti-periodic boundary traction $t$ (7) should be enforced on the opposite boundaries of the RVE model:

$$
\begin{aligned}
& u^{+}=u^{-} \\
& t^{+}=t^{-}
\end{aligned}
$$

Using numerical homogenization it is possible to model regular and irregular (stochastic) RVE elements (Fig. 4).

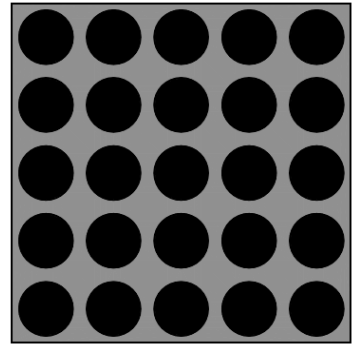

a

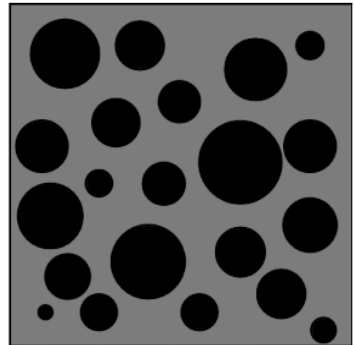

b
Fig. 4 RVE elements a - regular; b - irregular (stochastic)

\section{Models and results}

Using FEM the simplified models of foam metal structures were prepared. Here, the MSC.Software system was used. In RVE elements the size of voids, the number of voids (density) and position were changed. As a basic material assumed pure aluminium (Young modulus $E=69 \mathrm{GPa}$, Poisson ratio $v=0.33$ ).

Each RVE element was modelled as a cube measuring $5 \times 5 \times 5 \mathrm{~mm}$. The simplest element had one void with a radius of $2.25 \mathrm{~mm}$ centrally positioned (Fig. 5). The next regular RVE elements with different numbers of voids show
Figs. 6-9 and irregular RVE elements show Figs. 10-12. The parameters of regular RVE elements are presented in Table 1.

In the next step the boundary conditions were applied. Asked displacement values are chosen so that the value of deformation models was $\varepsilon=0.01$ and displacement in all directions were $u=0.05 \mathrm{~mm}$. RVE models that use the boundary conditions in the deformation, it is necessary averaging strains.

For each model were carried out six analyzes corresponding to the six types of boundary conditions. As a result of the analysis is obtained value of the stresses and strains per each item. This allows you to determine the value of the integral (1) and (2) numerically, that is to be summed generated by the program values for each item and then these values divided by the volume. As a result of this operation matrix medium stress and strain are obtained and then using the formula (4) the elasticity matrix of defined materials can be determined.
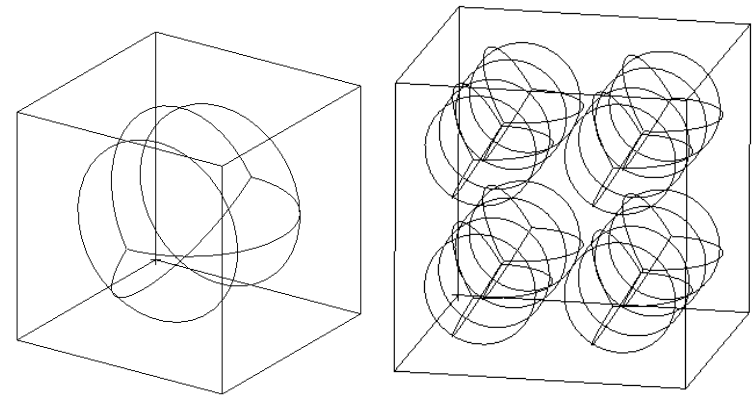

Fig. 5 Regular RVE model 1 Fig. 6 Regular RVE model 2
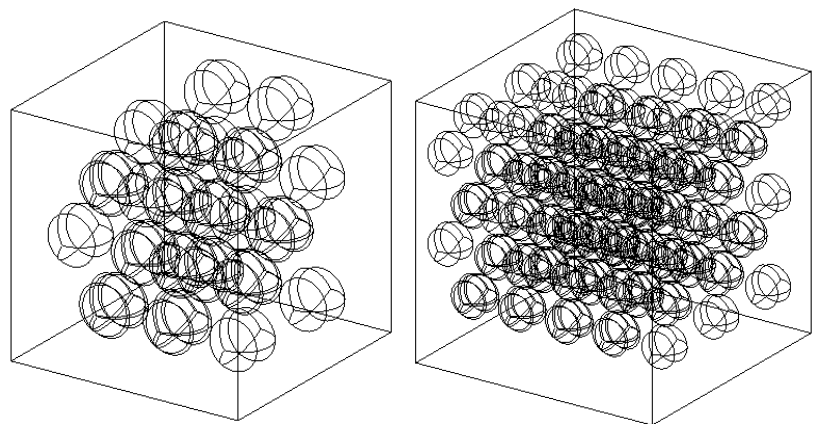

Fig. 7 Regular RVE model 3 Fig. 8 Regular RVE model 4 


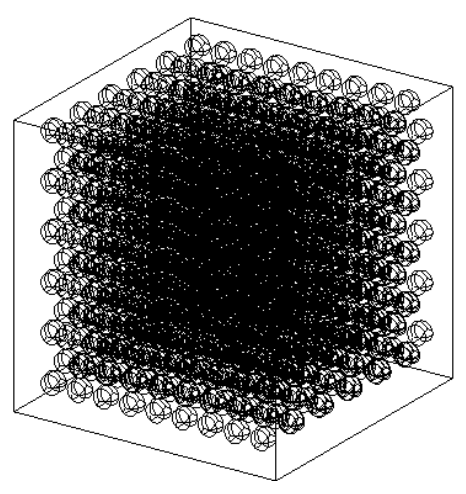

Fig. 9 Regular RVE model 5

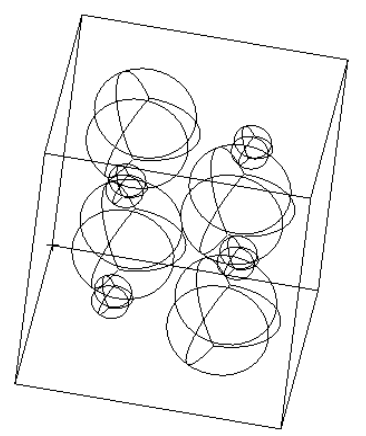

Fig. 10 Irregular RVE model 1

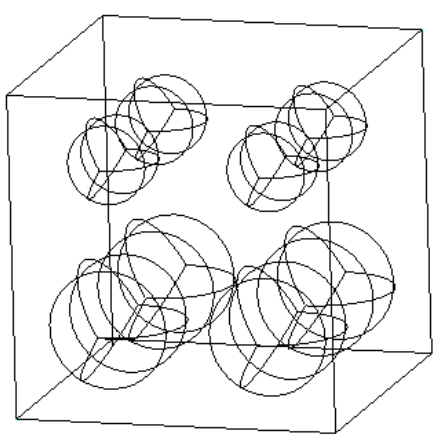

Fig. 11 Irregular RVE model 2

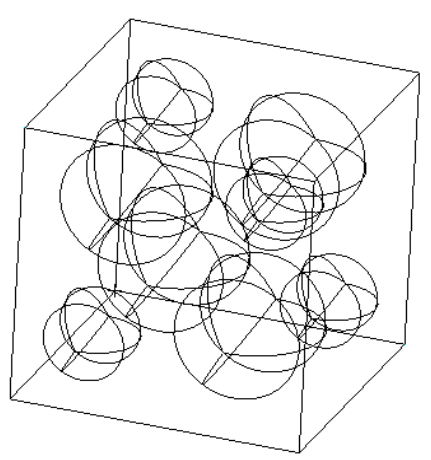

Fig. 12 Irregular RVE model 3

The parameters of regular RVE models

\begin{tabular}{|c|c|c|c|c|}
\hline Model & RVE dimensions, $\mathrm{mm}$ & Radius of void, $\mathrm{mm}$ & Numbers of voids & Density, g/mm ${ }^{3}$ \\
\hline 1 & $5 \times 5 \times 5$ & 2,25 & 1 & 61,8 \\
\hline 2 & $5 \times 5 \times 5$ & 1,1 & 8 & 64,3 \\
\hline 3 & $5 \times 5 \times 5$ & 0,7 & 21 & 75,4 \\
\hline 4 & $5 \times 5 \times 5$ & 0,4 & 121 & 74,0 \\
\hline 5 & $5 \times 5 \times 5$ & 0,2 & 1044 & 72,0 \\
\hline
\end{tabular}

Obtained results for regular RVE models are shown in Tables 2-6 and for irregular RVE models in Tables 7-9. Positions of material coefficients correspond to matrix $\mathrm{C}$ in Eq. (3).

We can observed that for regular RVE models that system of elasticity matrix tends to the isotropic structure.
The more voids that convergence is improved. For irregular RVE models designated elasticity matrix is full and asymmetrical.

The number, size and location of the voids significantly affects on the shape of the elasticity matrix and value of designated coefficients.

Table 2

Coefficients of elasticity matrix $\mathrm{C}$ for regular RVE model 1

\begin{tabular}{|c|c|c|c|c|c|c|}
\hline & $\mathrm{X}$ & $\mathrm{Y}$ & $\mathrm{Z}$ & $\mathrm{YZ}$ & $\mathrm{XZ}$ & $\mathrm{XY}$ \\
\hline $\mathrm{X}$ & 67226.8 & 34051.1 & 34894.4 & -108.8 & 20.3 & 0.9 \\
\hline $\mathrm{Y}$ & 34115.9 & 68673.4 & 35406.3 & 131.0 & -20.2 & 47.0 \\
\hline $\mathrm{Z}$ & 41352.3 & 41825.1 & 84130.4 & 23.5 & -0.9 & 6.1 \\
\hline $\mathrm{YZ}$ & -123.7 & -189.2 & -81.7 & 51351.7 & 5.1 & -8.7 \\
\hline $\mathrm{XZ}$ & 50.1 & -42.5 & 71.1 & 313.7 & 31982.0 & 37.1 \\
\hline $\mathrm{XY}$ & 176.3 & 93.8 & 23.8 & -58.2 & 2.8 & 31981.4 \\
\hline
\end{tabular}

Coefficients of elasticity matrix $\mathrm{C}$ for regular RVE model 2

\begin{tabular}{|c|c|c|c|c|c|c|}
\hline & $\mathrm{X}$ & $\mathrm{Y}$ & $\mathrm{Z}$ & $\mathrm{YZ}$ & $\mathrm{XZ}$ & $\mathrm{XY}$ \\
\hline $\mathrm{X}$ & 66736.5 & 33468.4 & 33468.4 & -0.0 & -0.0 & 0.0 \\
\hline $\mathrm{Y}$ & 33468.4 & 66736.4 & 33468.4 & -0.0 & -0.1 & 0.0 \\
\hline $\mathrm{Z}$ & 33468.4 & 33468.4 & 66736.5 & -0.0 & -0.1 & -0.0 \\
\hline $\mathrm{YZ}$ & -0.0 & 0.0 & 0.0 & 33268.0 & 0.0 & -0.0 \\
\hline $\mathrm{XZ}$ & -0.0 & -0.0 & -0.0 & 0.0 & 33268.04 & 0.0 \\
\hline $\mathrm{XY}$ & 0.0 & 0.0 & 0.0 & 0.0 & 0.0 & 33268.0 \\
\hline
\end{tabular}


Table 4

Coefficients of elasticity matrix $\mathrm{C}$ for regular RVE model 3

\begin{tabular}{|c|c|c|c|c|c|c|}
\hline & $\mathrm{X}$ & $\mathrm{Y}$ & $\mathrm{Z}$ & $\mathrm{YZ}$ & $\mathrm{XZ}$ & $\mathrm{XY}$ \\
\hline $\mathrm{X}$ & 78224.5 & 39229.7 & 39229.7 & -0.0 & -0.0 & -0.1 \\
\hline $\mathrm{Y}$ & 39229.7 & 78224.5 & 39229.7 & -0.0 & -0.1 & -0.0 \\
\hline $\mathrm{Z}$ & 39229.7 & 39229.7 & 78224.5 & -0.0 & -0.1 & -0.1 \\
\hline $\mathrm{YZ}$ & 0.0 & -0.0 & 0.0 & 38994.8 & 0.0 & -0.0 \\
\hline $\mathrm{XZ}$ & -51.5 & -26.6 & -24.5 & 577.1 & 38993.3 & -0.0 \\
\hline $\mathrm{XY}$ & 0.0 & 0.0 & -0.0 & 0.0 & 0.0 & 38994.8 \\
\hline
\end{tabular}

Coefficients of elasticity matrix $\mathrm{C}$ for regular RVE model 4

\begin{tabular}{|c|c|c|c|c|c|c|}
\hline & $\mathrm{X}$ & $\mathrm{Y}$ & $\mathrm{Z}$ & $\mathrm{YZ}$ & $\mathrm{XZ}$ & $\mathrm{XY}$ \\
\hline $\mathrm{X}$ & 76803.7 & 38517.2 & 38517.2 & 0.0 & 0.0 & 0.1 \\
\hline $\mathrm{Y}$ & 38517.1 & 76803.7 & 38517.2 & 0.0 & 0.0 & 0.0 \\
\hline $\mathrm{Z}$ & 38517.2 & 38517.2 & 76803.7 & 0.0 & 0.0 & 0.0 \\
\hline $\mathrm{YZ}$ & 0.0 & 0.0 & 0.0 & 38286.5 & 0.0 & 0.0 \\
\hline $\mathrm{XZ}$ & 0.0 & -0.0 & -0.0 & 0.0 & 38286.5 & -0.0 \\
\hline $\mathrm{XY}$ & 0.0 & 0.0 & 0.0 & -0.0 & 0.0 & 38286.5 \\
\hline
\end{tabular}

Coefficients of elasticity matrix $\mathrm{C}$ for regular RVE model 5

\begin{tabular}{|c|c|c|c|c|c|c|}
\hline & $\mathrm{X}$ & $\mathrm{Y}$ & $\mathrm{Z}$ & $\mathrm{YZ}$ & $\mathrm{XZ}$ & $\mathrm{XY}$ \\
\hline $\mathrm{X}$ & 74719.7 & 37472.0 & 37472.0 & -0.0 & 0.0 & 0.0 \\
\hline $\mathrm{Y}$ & 37472.0 & 74719.7 & 37472.0 & -0.0 & 0.0 & -0.0 \\
\hline $\mathrm{Z}$ & 37472.0 & 37472.0 & 74719.7 & -0.0 & 0.0 & -0.0 \\
\hline $\mathrm{YZ}$ & -0.0 & -0.0 & 0.0 & 37247.6 & -0.0 & -0.0 \\
\hline $\mathrm{XZ}$ & -0.0 & -0.0 & -0.0 & -0.0 & 37247.6 & 0.0 \\
\hline $\mathrm{XY}$ & -0.0 & -0.0 & -0.0 & -0.0 & -0.0 & 37247.6 \\
\hline
\end{tabular}

Coefficients of elasticity matrix $\mathrm{C}$ for irregular RVE model 1

Table 7

\begin{tabular}{|c|c|c|c|c|c|c|}
\hline & X & Y & Z & YZ & XZ & XY \\
\hline$X$ & 84269.5 & 39025.7 & 44202.9 & -47.1 & 5036.4 & 86.4 \\
\hline$Y$ & 44607.7 & 83538.3 & 46846.3 & -49.9 & 5337.5 & 91.5 \\
\hline Z & 37726.5 & 34979.4 & 81798.7 & -42.3 & 4514.2 & 77.4 \\
\hline$Y Z$ & -473.1 & -438.6 & -496.8 & 42179.3 & -56.5 & -0.9 \\
\hline$X Z$ & -2130.2 & -1975.1 & -2237.1 & 2.3 & 41923.9 & -4.3 \\
\hline$X Y$ & -515.9 & -478.3 & -541.8 & 0.5 & -61.7 & 42177.7 \\
\hline
\end{tabular}

Coefficients of elasticity matrix $\mathrm{C}$ for irregular RVE model 2

Table 8

\begin{tabular}{|c|c|c|c|c|c|c|}
\hline & X & Y & Z & YZ & XZ & XY \\
\hline X & 82196.2 & 42516.6 & 42641.0 & -997.6 & -151.7 & -758.5 \\
\hline Y & 39182.2 & 82323.2 & 40998.5 & -959.1 & -142.8 & -729.2 \\
\hline Z & 37299.0 & 38914.1 & 80472.3 & -913.0 & -136.0 & -694.2 \\
\hline YZ & -302.1 & -315.1 & -286.0 & 41451.6 & 1.1 & 5.8 \\
\hline XZ & -449.1 & -468.6 & -470.0 & 10.9 & 41445.9 & 8.3 \\
\hline XY & -466.3 & -486.5 & -503.7 & 11.4 & 1.7 & 41452.8 \\
\hline
\end{tabular}

Coefficients of elasticity matrix $\mathrm{C}$ for irregular RVE model 3

\begin{tabular}{|c|c|c|c|c|c|c|}
\hline & $\mathrm{X}$ & $\mathrm{Y}$ & $\mathrm{Z}$ & $\mathrm{YZ}$ & $\mathrm{XZ}$ & $\mathrm{XY}$ \\
\hline $\mathrm{X}$ & 69319.4 & 34285.2 & 37306.5 & -222.2 & -25.6 & -648.8 \\
\hline $\mathrm{Y}$ & 35070.2 & 69459.6 & 37782.3 & -225.3 & -26.0 & -657.4 \\
\hline $\mathrm{Z}$ & 29553.0 & 29299.2 & 66618.2 & -189.8 & -21.9 & -554.4 \\
\hline $\mathrm{YZ}$ & -445.9 & -442.0 & -481.0 & 34740.0 & 0.3 & 8.3 \\
\hline $\mathrm{XZ}$ & -529.9 & -493.4 & -536.9 & 3.4 & 34737.6 & 9.5 \\
\hline $\mathrm{XY}$ & -136.9 & -135.7 & -147.7 & 0.9 & 0.1 & 34739.7 \\
\hline
\end{tabular}




\section{Discussion and conclusions}

In the literature one can find works using numerical homogenization of the bone scaffold structures [11], of materials with internal cracks [12]. However, most studies have been associated with the analysis of composite with inclusions of various size, number and arrangement relating to the different types of matrix material and the inclusions [13]. Most of this works was based on homogenization of the RVE 2D models.

In this study developed 3D model of RVE elements and the coefficients of elasticity matrix were determined for different number and size of voids and their various positions. It means that influence of geometrical features on material parameters was tested.

It can be observed that if the inclusions grid is regular then density primarily influence on coefficient of elasticity matrix $\mathrm{C}$. However changing the size of inclusions in some plane or direction we have impact on the form of matrix $\mathrm{C}$, which gives us to understand that if we will skillfully control the composite geometry we will be able to model its mechanical parameters.

In further studies, the results (material constants) will be used to develop and stress analysis of complex systems containing elements made of foamed metal type structures. This should result in significantly shorten the time of calculation.

\section{References}

1. Material-Applications-guide. ERG Aerospace Corporation. [accessed 9 March 2016]. Available from Internet: http://www.ergaerospace.com/Material-Applicationsguide.html.

2. Yu, C.; Banhart, J. 1998. Mechanical Properties of Metallic Foams, IFAM [accessed 9 March. 2016]. Available from Internet: http://www.helmholtz-berlin.de/me$\mathrm{dia} / \mathrm{media} / \mathrm{spezial} / \quad$ people/banhart/html/B-Conferences/b020_yu1998.pdf.

3. Andersen, O. 2016. Cellular metallic structures, Fraunhofer IFAM [accessed 9 March. 2016]. Available from Internet: (in German) http://www.ifam.fraunhofer. $\mathrm{de} /$ content/dam/ifam/de/documents/dd/In-

fobl\%C3\%A4tter/zellulare_metallische_werkstoffe_fraunhofer_ifam_dresden.pdf.

4. Sobczak, J. 2005. Highly porous materials, Foundry Research Institute Kraków, 172 p. (in Polish).

5. Ashby, M.F. 2000. Metal Foam A Design Guide. Butterworth Heinemann, Boston 456 p.

6. Hanssena, A.G.; Girard, Y.; Olovsson, L; Berstad, T.; Langseth, M. 2006. A numerical model for bird strike of aluminium foam-based sandwich panels, Int. Journal of Impact Engineering 32: 1127-1144. http://dx.doi.org/10.1016/j.ijimpeng.2004.09.004.
7. Oczoś, K. 2010. Aluminium foam - properties, the manufacture, use, Mechanik 5-6/2010: 309-317 (in Polish).

8. Innovative solutions for lightweight construction. Aluminium foam sandwiches and $3 \mathrm{~d}$ mouldings. Havel metal foam. [accessed 9 March. 2016]. Available from Internet: http://www.havel-mf.de/index_en.html.

9. Kouznetsova, V.G.; Geers, M.G.D.; Brekelmans, V.A.M. 2004. Multi-scale second-order computational homogenization of multi-phase materials: a nested finite element solution strategy, Comput. Methods Appl. Mech. Eng. 194: 5525-5550.

http://dx.doi.org/10.1016/j.cma.2003.12.073.

10. Zohdi, I.T. 2004. Homogenization Methods and Multiscale Modleling. Encyclopedia of Computational Mechanics. Solids and Structures, John Wiley \& Sons, 407430.

11. Makowski, P.; John, A.; Kuś, W.; Kokot, G. 2013. Multiscale modeling of the simplified trabecular bone structure, Mechanika, Proc. of the $18^{\text {th }}$ Int. Conf. Mechanika 2013, Kaunas: 156-161.

12. Czyż, T.; Dziadkiewicz, G.; Fedeliński, P.; Górski, R.; Ptaszny, J. 2013 Advanced Computer Modelling in Micromechanics, Publisher Silesian University of Technology, Gliwice. 132p.

13. Beluch, W.; Burczyński, T.; Długosz, A. 2007. Evolutionary multi-objective optimization of hybrid laminates, Computer Assisted Mechanics and Engineering Sciences 14(4): 569-578.

A. John, M. John, A. Bartela

\section{NUMERICAL HOMOGENIZATION OF THE FOAMED METAL STRUCTURES}

\section{S u m m a r y}

In the paper multi-scale modeling of the foamed metal structures using numerical homogenization algorithm is prescribed. The first, numerical model of heterogeneous porous simplified structures of typical foamed metal, based on the FEM was built. Next, a micro RVE model representing elementary volume of macroscopic model was constructed. Material parameters of the considered structure were determined with use of numerical homogenization algorithm. In the work the different RVE models of structure were created and their properties were compared at different relative density, different numbers and the size and structure of the arrangement of voids.

Keywords: foamed metal, numerical homogenization, FEM, RVE.

Received January 21, 2016 Accepted September 28, 2016 